$3-1-2012$

\title{
Probe Functionalization With A Rhop-3 Antibody: Toward A Rhop-3 Antigen Immunosensor For Detection of Malaria
}

\author{
Salaam Saleh \\ Cleveland State University \\ Susan Moreno Molek \\ Perera N. Indika \\ Cleveland State University \\ Alan Riga \\ Clevland State University \\ Tobili Sam Yellowe \\ Cleveland State University
}

Cleveland State University, s.moreno@csuohio.edu

Follow this and additional works at: https://engagedscholarship.csuohio.edu/scichem_facpub See next page for additional authors

Part of the Chemistry Commons

How does access to this work benefit you? Let us know!

\section{Publisher's Statement}

The final publication is available at Springer via http://dx.doi.org/10.1007/s00216-012-5735-y

\section{Recommended Citation}

Saleh, Salaam; Molek, Susan Moreno; Indika, Perera N.; Riga, Alan; Yellowe, Tobili Sam; and Bayachou, Mekki, "Probe Functionalization With A Rhop-3 Antibody: Toward A Rhop-3 Antigen Immunosensor For Detection of Malaria" (2012). Chemistry Faculty Publications. 325.

https://engagedscholarship.csuohio.edu/scichem_facpub/325

This Article is brought to you for free and open access by the Chemistry Department at EngagedScholarship@CSU. It has been accepted for inclusion in Chemistry Faculty Publications by an authorized administrator of EngagedScholarship@CSU. For more information, please contact library.es@csuohio.edu. 


\section{Authors}

Salaam Saleh, Susan Moreno Molek, Perera N. Indika, Alan Riga, Tobili Sam Yellowe, and Mekki Bayachou 


\title{
Probe functionalization with a Rhop-3 antibody: toward a Rhop-3 antigen immunosensor for detection of malaria
}

\author{
Salaam Saleh • Susan Moreno-Molek • Indika Perera • \\ Alan Riga • Tobili Sam-Yellowe • Mekki Bayachou
}

\begin{abstract}
The antibody specific for the malaria protein, Rhop-3, and FL-Rhop-3, were immobilized on the surface of a gold electrode modified with cysteamine. Colloidal gold was used to enhance the detection signal for Rhop-3 antigens. The Rhop-3 antibody was also immobilized on gold electrodes preactivated with dithiobis(succinimidyl proprionate) (DSP). Immobilization was performed at room temperature and at $37{ }^{\circ} \mathrm{C}$. Cyclic voltammetry $(\mathrm{CV})$ was used to monitor the interaction between the immobilized antibody and its cognate antigen in solution, using ferricyanide, $\mathrm{K}_{3} \mathrm{Fe}(\mathrm{CN})_{6}$, as reporting electroactive probe. Tests indicate recognition of Rhop-3 protein by the immobilized antibody. Antigen recognition was enhanced by incubation at $37{ }^{\circ} \mathrm{C}$ compared with room-temperature incubation. Our results suggest that an immunosensor can be developed and optimized to aid detection of Rhop-3 antigens in samples
\end{abstract}

from malaria patients. As far as we are aware, this is the first amperometric immunosensor targeting Rhop-3 antigen as a malaria biomarker.

Keywords Immunosensor - Antibody immobilization · Malaria diagnosis · Plasmodium falciparum $\cdot$ Rhop-3 $\cdot$ Rapid diagnostic test

\section{Introduction}

Malaria is a disease caused by infection with protozoan parasites of the genus Plasmodium. The parasites are transmitted to humans by a mosquito vector of the genus Anoph eles. Four species of Plasmodium parasites cause malaria in humans, $P$. falciparum, $P$. vivax, $P$. malariae, and $P$. ovale. $P$. falciparum and $P$. vivax cause the most infections worldwide, with $P$. falciparum predominating in Africa and $P$. vivax predominating in South America and Asia. P. falcipa rum is also the cause of the most severe illnesses and deaths [1]. Recent estimates suggest that 1 to 3 million deaths, and 515 million cases of malaria occur each year. Most malaria deaths are children, with an alarming estimated average of four children per minute. Malaria morbidity and mortality remain significant in many parts of the world [1].

Current diagnostic methods for malaria include microscopy and immunologic rapid diagnostic tests (RDTs). Three proteins are currently being tested for use in RDTs: $P$. falciparum histidine-rich protein 2 (PfHRP2), $P$. falciparum lactate dehydrogenase (PfLDH), and aldolase [2, 3].

Literature reports of $P$. falciparum geographic variants that do not express PfHRP pose a challenge for the use of current PfHRP-based RDTs for malaria diagnosis [4-6]. Improved methods for malaria diagnosis are required to enable accurate diagnosis and effective early intervention 
and treatment of malaria. Antigen recognition by specific antibodies forms the basis of immunosensors designed for use in diagnosis of a broad range of infectious and chronic diseases [7-9]. Immunosensors designed to detect specific peptides, antigen epitopes, or antibodies are used for chronic and infectious diseases [10]. Serological studies using sera of malaria-infected individuals from different geographic regions showed that the C-terminus of Rhop3 is structurally conserved among different geographical and laboratory $P$. falciparum isolates [11, 12]. Because of its involvement in erythrocyte invasion, Rhop3 has been regarded as an ideal candidate for a vaccine and for diagnostic studies.

The purpose of this study was to develop an immunosensor capable of detecting Plasmodium antigens in patient samples. An amperometric immunosensor for detection of PfHRP2 has been shown to enable highly sensitive detection of antiPfHRP2 in human serum [13]. However, because of the variations observed in PfHRP2 [4] and the absence of PfHRP2 in some geographic $P$. falciparum strains $[5,6,14]$, there is a need to identify other $P$. falciparum antigens that can serve as important biomarkers for malaria diagnosis $[2,3]$.

In this communication, we report a first attempt to generate an immunosensor that can identify the Rhop-3 malaria protein. An antibody specific for $P$. berghei Rhop-3 was immobilized on gold electrodes by use of both cysteamine and DSP linking strategies. Antigen recognition was optimum at $37^{\circ} \mathrm{C}$.

\section{Materials and methods}

\section{Recombinant proteins}

The full length (FL) P. berghei Rhop-3 gene was amplified by polymerase chain reaction (PCR), by use of primers containing appropriate restriction sites, digested, and cloned into pRSET (version A) (Invitrogen, San Diego, CA, USA), using methods described elsewhere [15], to generate a fusion protein containing a six-histidine tag. The plasmid pRSETA was transformed into Escherichia coli strain BL21.DE3. After culture at $37^{\circ} \mathrm{C}$ until the $\mathrm{OD}_{600}$ was 0.7 , recombinant protein expression was induced by addition of IPTG at a final concentration of $1 \mathrm{mmol} \mathrm{L}^{1}$. Expressed protein was detected by use of rabbit antibody 686 [12] and western blotting. Antibody 686 is specific for P. falciparum Rhop-3 [12]. The Coomassie blue SDS-PAGE gel obtained from the purification scheme for the $100-\mathrm{kDa} P$. berghei recombinant protein (His-FLPbRhop-3) is shown in Electronic Supplementary Material Fig. S1. The recombinant full-length protein was purified by use of nickel-chelate chromatography $\left(\mathrm{Ni}^{2+}-\mathrm{NTA}\right.$-agarose from Qiagen, Chatsworth, CA, USA) under denaturing conditions using $8 \mathrm{~mol} \mathrm{~L}{ }^{1}$ urea. The recombinant protein, designated His-
FLPbRhop-3, from 10-L large-scale cultures was dialyzed against 1 XPBS with $0.1 \%$ Triton, concentrated using a highspeed vacuum centrifuge (Savant Instruments, Holbrook, NY, USA) and after protein estimation by use of the Bradford method [16]. One milligram of FLPbRhop-3 was obtained [15]. The recombinant protein FLPbRhop-3 was used to produce monospecific polyclonal antibodies in rabbits as described elsewhere [15]. Antibody specificity to the FLPbRhop-3 recombinant protein was evaluated. The antibody titers were determined and the reactivity of the antibodies to native Rhop-3 in immunoelectron microscopy was obtained [15]. P. falciparum schizont extracts were obtained by subjecting schizont pellets [17] to three freeze-thaw cycles in $1 \times$ PBS. After centrifugation at $14,000 \mathrm{~g}$, supernatant containing schizont proteins was collected in an Eppendorf tube for use in antibody binding by western blotting.

\section{Antibody immobilization}

Antibody immobilization on gold electrodes (CH Instruments, Austin, TX, USA) was performed by use of cysteamineglutaraldehyde chemistry [9] or dithiobis(succinimidyl propionate) (DSP)-modified gold electrodes [18] in a preliminary study to establish conditions for immobilization of Rhop-3specific antibodies. Incubation was performed at room temperature or at $37^{\circ} \mathrm{C}$. A slightly modified method of glutaraldehyde covalent crosslinking was used [9]. Gold electrodes were polished with alumina slurries for 10-15 min, sonicated, rinsed with distilled water, and then cycled between 0 and $+1.6 \mathrm{~V}$ at $100 \mathrm{mV} \mathrm{s}{ }^{1}$ in $0.1 \mathrm{~mol} \mathrm{~L}^{1} \mathrm{H}_{2} \mathrm{SO}_{4}$ solution to obtain a stable background voltammogram. The electrodes were incubated with $0.02 \mathrm{~mol} \mathrm{~L}^{1}$ cysteamine aqueous solution for $12 \mathrm{~h}$ then rinsed in water and incubated in $12 \%(v / v)$ glutaraldehyde for $1 \mathrm{~h}$. The resulting surface was rinsed with water and incubated in cyteamine for another $12 \mathrm{~h}$, followed by washing with deionized water to remove any physically adsorbed molecules. The electrodes were incubated in $1 \mathrm{~mL}$ 10-nm colloidal gold (Sigma Chemicals, St Louis, MO, USA) for $10 \mathrm{~h}$ to form an enhancing layer of gold nanoparticles. The added gold nanoparticles result in an increase in the density of sites for antibody immobilization on the gold electrode. An AFM image of early-stage immobilization of gold nanoparticles on a highly oriented pyrolytic graphite substrate (HOPG) grafted with linkers having free thiols that serve to attach the gold nanoparticles, just as is the case on our gold electrodes, is shown in Electronic Supplementary Material Fig. S2.

In initial studies, we investigated the use of both rabbit monospecific polyclonal antisera \#686 [12] and mouse monospecific polyclonal antisera FLRhop-3 specific for $P$. falciparum and $P$. bergheii Rhop-3 proteins, respectively. Specificity of FLRhop-3 antibody was confirmed by 
immunoassays, for example western blotting, immunofluorescence, and immunoprecipitation [15]. FLRhop-3 antibody was shown to react with the $100-\mathrm{kDa}$ Rhop- 3 protein by western blotting at a dilution of 1:1000 [15]. FLRhop-3 antibody reactivity with FLRhop-3 was evaluated in native immunoassays (immunoprecipiation and immunofluorescence). Antibody dilutions of 1:10-1:1000 were used in immunoassays; native immunoprecipitation (1:10), western blotting, and immunofluorescence $(1: 1000)$. On the basis of these results a dilution of 1:50 was used for antibody immobilization to gold electrodes in this initial study. Incubation times and temperature were optimized for antibody immobilization experiments. The methods presented here are for FLRhop-3 antibody only.

The modified electrodes were incubated in mouse antisera FL-Rhop-3 diluted 1:50 in 1× PBS [15]. Gold electrodes were incubated in antisera for $12 \mathrm{~h}$, rinsed in $1 \times \mathrm{PBS}$, and then immersed in $1 \mathrm{mg} \mathrm{mL}^{1}$ bovine serum albumin (BSA) for $1 \mathrm{~h}$ to block non-specific sites on the electrode [9]. After washing in $1 \times$ PBS, the electrodes were stored at $4{ }^{\circ} \mathrm{C}$ before use in antigen recognition tests.

For modification with DSP chemistry, clean gold electrodes were incubated in DSP solutions for $2 \mathrm{~h}$, washed with deionized water, and incubated with FLRhop-3 antisera diluted 1:50, for $1 \mathrm{~h}$. The electrodes were washed in $1 \times$ PBS, blocked in $1 \mathrm{mg} \mathrm{mL}^{1}$ BSA for $1 \mathrm{~h}$, and washed again in $1 \times$ PBS, followed by incubation in $6 \mu \mathrm{g} \mathrm{mL}{ }^{1}$ FLRhop-3 for $1 \mathrm{~h}$. As a negative control, the DSP-modified electrodes with immobilized FLRhop3 antibodies were incubated with $6 \mu \mathrm{g} \mathrm{mL}{ }^{1}$ chicken ovalbumin in lieu of the target antigen for $1 \mathrm{~h}$. The schematic workflow for the process of antibody immobilization and antigen detection is shown in Fig. 1. In this preliminary work, we used only recombinant proteins as target antigen to establish conditions necessary for protein detection with the immunosensor being developed. Therefore, correlations of parasite densities with purified protein levels were not performed. Such correlations will be investigated in future studies.

\section{Voltammetry}

Cyclic voltammetry was used to assess the efficiency of antigen binding. Cyclic voltammetry was performed in a three-electrode cell. All potentials reported are relative to the $\mathrm{Ag} / \mathrm{AgCl}$ reference system. The working electrode was the modified gold electrode with a platinum wire serving as the counter electrode. The potential window scanned was between -0.2 and $+0.6 \mathrm{~V}$. Electrochemical analysis was performed on the electrodes at various stages of the modification process, and before and after incubation with antigen for $1 \mathrm{~h}$ to evaluate binding recognition efficiency.

In terms of its application to detection of Rhop-3 antigens in this initial stage, the cyclic voltammetry method takes advantage of changes of current generated by a freely diffusing redox probe (ferricyanide in this case) to the underlying surface of the modified immunosensor. Binding of bulky Rhop-3 target proteins on the surface is expected to compromise the extent of access of the redox probe to the underlying electrode. A decrease in current will then signal and quantify binding of the target protein on the antibody sites on the immunosensor. This explains the amperometric detection of Rhop-3 in this initial work.

\section{Results and discussion}

Recognition proteins, for example antibodies, may be directly adsorbed on hydrophobic surfaces, for example electrode interfaces. However, this usually leads to denaturation and/or disruption of the recognition of the target protein. Even when the native structure of the adsorbed antibody is preserved, binding may be limited by steric hindrance of recognition sites. In an effort to preserve Rhop-3 recognition by antibodies, we took advantage of bifunctional linkers such as $\beta$-mercaptoethylamine (cysteamine) or dithiobis (succinimidyl propionate) (DSP) to provide point-covalent binding to surface lysine residues on the antibody targeted
Fig. 1 Schematic

representation of electrode modification with linker (either DSP or cysteamine glutaraldehyde) and $10 \mathrm{~nm}$ gold nanoparticles (spheres). Anti body is immobilized using CHO (glutaraldehyde) or NHS (DSP) chemistry before use for antigen recognition

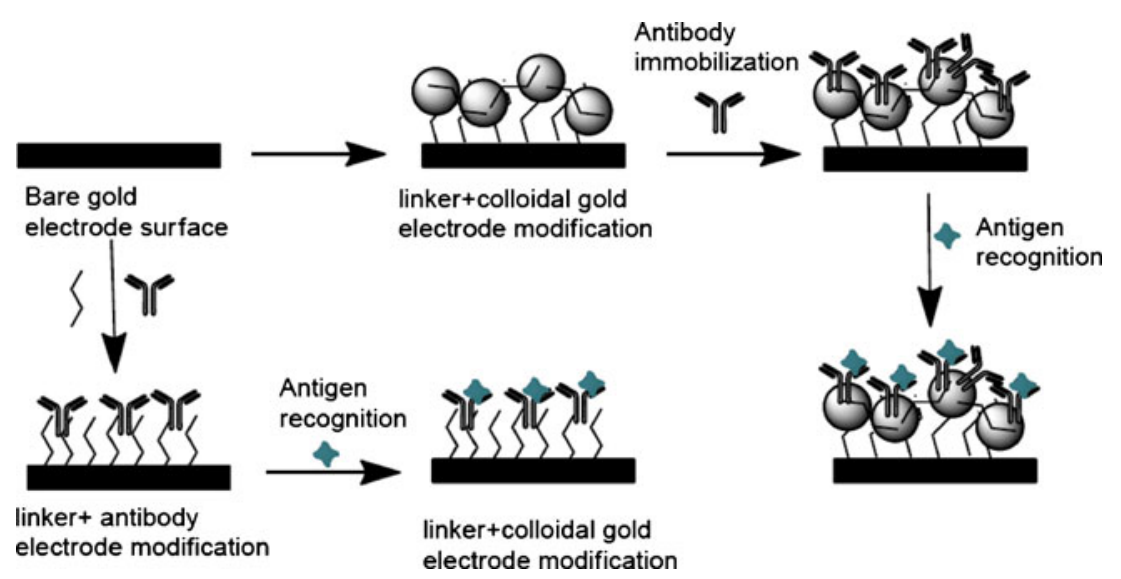


for immobilization; a thiol group on the same linker served for binding to the gold surface or to gold nanoparticles $(10 \mathrm{~nm})$ on an underlying gold surface. The different steps of antibody immobilization for both methods are shown in Fig. 1. Figure 2 shows the typical electrode response at different stages of the assay using the cysteamine-glutaraldehyde immobilization of anti-Rhop-3. First, the cysteamine treatment introduces amino functionality on to the electrode surface. Second, glutaraldehyde preactivation of the electrode is performed to ensure subsequent multipoint attachment of the recognition antibodies in question $[19,20]$.

Figure 2 shows that the voltammetric current decreases upon immobilization of anti-FLRhop-3 on the cysteamineglutaraldehyde-preactivated electrode surface. The current decrease is expected, because attachment of the bulky antibody molecules reduces access of the ferricyanide used as reporting redox probe. Antigen recognition should normally be accompanied by a further reduction of current as a result of Rhop-3 proteins binding to the surface. Although there is a small current decrease upon introduction of Rhop-3 target molecules, the recorded current change is very minimal and may not be attributed to specific recognition of Rhop-3 proteins. The immobilization of recognition proteins using glutaraldehyde-preactivated surfaces is simple and efficient; however, this method is also known to result in immobilized proteins with lower recognition capability. In fact, potential multipoint cross-linking may result in altered conformations, which can reduce recognition. The altered antibody response may also be the result of changes in the microenvironment because of glutaraldehyde preactivation and/or a non-uniform layer of immobilized antibodies.

In effort to improve Rhop-3 recognition by immobilized antibodies, we investigated another immobilization strategy, one that uses a molecular linker with a

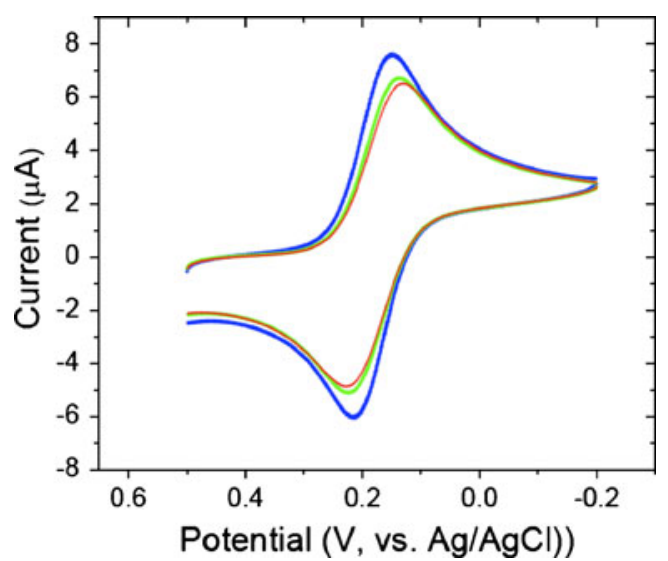

Fig. 2 Cyclic voltammetry response of a gold electrode modified with cysteamine glutaraldehyde (blue trace) followed by anti FLRhop 3 immobilization (green trace). Electrode response on addition of Rhop $3\left(60 \mu \mathrm{g} \mathrm{mL}^{1}\right)$ (red trace). Scan rate used is $0.1 \mathrm{Vs}^{1}$ preactivated end that targets single primary amines on the surface of the antibody.

In this modified strategy, a homobifunctional linker, dithiobis(succinimidyl propionate) (DSP), was used for electrode modification and for antibody immobilization. DSP is one of the thiolated precursors known to form selfassembled monolayers on gold surfaces. It is also used to attach recognition bioelements to gold nanoparticles. First, its disulfide linkage undergoes direct reductive chemisorption resulting in a self-assembled monolayer on the gold support. This leaves the preactivated NHS group ready to react with available primary amines (for example lysines) on a protein of choice. In our case, the surface amine groups on the antibody proteins replaced the NHS groups on the DSP, forming covalent linkages with the gold surface. Similar to the cysteamine case, covalent immobilization of antiFLRhop-3 antibodies on DSP-modified electrode results in a reduced current, indicating successful immobilization of antibody proteins. Incubation of the anti-FLRhop-3-modified electrode in a solution containing Rhop-3 proteins $\left(60 \mu \mathrm{g} \mathrm{mL}{ }^{1}\right)$ at $37{ }^{\circ} \mathrm{C}$ results in a further decrease in current, consistent with limited access of the ferricyanide reporting redox probe to the electrode surface. Binding of the target Rhop-3 protein limits this access and these results indicate positive recognition and binding of Rhop-3 proteins by the immobilized specific antibody. Figure 3 shows the differential voltammogram representing the current difference between the consecutive steps of antibody immobilization and antigen (Rhop-3) recognition. Although the decrease in current on Rhop-3 binding was small, it is significant, and it is much larger than the decrease obtained with cysteamine-glutaraldehyde immobilization.

It is important to report that the relative current decrease on exposure to Rhop-3 solution was also accompanied by a

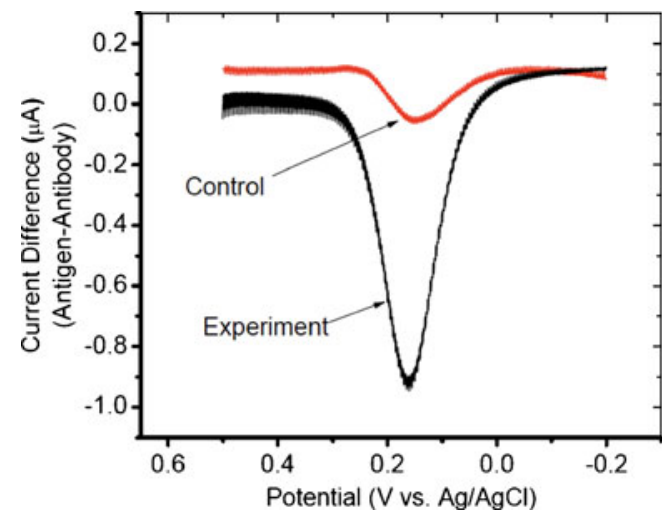

Fig. 3 Differential current response (i.e. response of antigen minus response of antibody). Voltammetry recorded in the absence and pres ence of $60 \mu \mathrm{g} \mathrm{mL}{ }^{1}$ Rhop 3 on a DSP antibody modified gold elec trode. Scan rate used is $0.1 \mathrm{Vs} \mathrm{s}^{1}$. Control signal was recorded in the presence of $60 \mu \mathrm{g} \mathrm{mL}{ }^{1}$ chicken ovalbumin in lieu of the Rhop 3 target 
slight increase in peak-to-peak potential difference $(\sim 33 \mathrm{mV}$ increase in $\Delta E_{\mathrm{p}}$ measured by cyclic voltammetry). The $\Delta E_{\mathrm{p}}$ change is also an indication of binding of Rhop-3 targets on the antibody-modified interface. The increase of $\Delta E_{\mathrm{p}}$ indicates that the rate of electron transfer to the redox probe becomes relatively sluggish [21]. The compromised electron-transfer kinetics may be the result of a modified microenvironment on the electrode surface which, in part, may alter the needed ion transfers to buried sites where the redox reporter exchanges an electron with the underlying electrode. Although the results of this initial work demonstrate the possibility of preparation of an immunosensor that can recognize Rhop-3 malaria antigen, systematic and detailed studies of stability, reproducibility, and reusability were not carried out at this feasibility stage. One reason is that the method of detection based on redox probe access is not robust and was used for demonstration purposes only for this early proof of principle.

In terms of controls, we tested the response of our immunosensor to chicken ovalbumin, to contrast it with the specific recognition of Rhop-3 proteins. Figure 3 shows the differential response obtained when the antibodymodified electrode was exposed to a solution of chicken ovalbumin for $1 \mathrm{~h}$, in lieu of the target Rhop-3 antigen. Figure 3 shows that the peak current obtained with $60 \mu \mathrm{g} \mathrm{mL}{ }^{1}$ chicken ovalbumin is much smaller than that obtained with the target Rhop-3 proteins, and indicates that our electrochemical immunosensor enables specific recognition of Rhop-3 proteins.

Although this communication and the detection strategy relying on access of ferricyanide to the electrode surface provides a proof of principle for our immunosensor based on Rhop-3 antibody, other known detection strategies, based, for instance, on secondary enzymatic reactions, can be coupled to our immobilization method and may give better detection sensitivity. In this regard, and in an effort to increase the sensitivity of our electrochemical immunosensor, we are now investigating other methods, including the use of nanostructured surfaces to enhance the capture of the antigen from test samples and the use of enzyme-labeled secondary antibodies to enhance signal transduction.

\section{Conclusions}

This work is a first attempt to generate an immunosensor that targets the Rhop-3 malaria protein. We successfully immobilized antibodies against recombinant full length Rhop-3 protein to cysteamine-modified and DSP-modified gold electrodes. Rhop-3 antigen detection was achieved, with optimum antigen binding at $37{ }^{\circ} \mathrm{C}$. Detection of PfHRP2 in clinical samples has been shown to depend on parasite density and concentration of PfHRP2 in blood. In future studies, we will evaluate the concentration correlation with parasite densities using our sensor, which targets the Rhop-3 antigen. Conserved P. falcipa rum blood stage antigens that can be identified in blood and other patient samples are alternative choices for malaria diagnostic biomarkers. After antibody immobilization, antigen detection is a one-step process. A simple and sensitive procedure for detection of antigen in patient samples will enable accurate malaria diagnosis and efficient monitoring of malaria drug treatment. Further development of the Rhop-3 immunosensor includes optimizing antigen and antibody concentrations to improve the sensitivity of antigen detection. We are also investigating other methods, including the use of nanostructured surfaces to enhance antigen capture from the bulk of the sample coupled with use of enzyme-labeled secondary antibodies to enhance signal transduction.

Acknowledgements Research funding was provided by Cleveland State University's Undergraduate Summer Research Program 2010 to both MB and TSY. Other support from an FRD grant (CSU Ohio Board of Regents) and NSF (grant CHE 0848820) to MB is also recognized.

\section{References}

1. Clark IA, Budd AC, Alleva LM, Cowden WB (2006) Malar J $5: 85$

2. Makler MT, Piper RC (2009) Am J Trop Med Hyg 81:921 926

3. Urdea M, Penny LA, Olmsted SS, Giovanni MY, Kaspar P, Shepherd A, Wilson P, Dahl CA, Buchsbaum S, Moeller G, Hay Burgess DC (2006) Nature 444(Suppl 1):73 79

4. Baker J, Ho MF, Pelecanos A, Gatton M, Chen N, Abdullah S, Albertini A, Ariey F, Barnwell J, Bell D, Cunningham J, Djalle D, Echeverry DF, Gamboa D, Hii J, Kyaw MP, Luchavez J, Membi C, Menard D, Murillo C, Nhem S, Ogutu B, Onyor P, Oyibo W, Wang SQ, McCarthy J, Cheng Q (2010) Malar J 9:129

5. Gamboa D, Ho MF, Bendezu J, Torres K, Chiodini PL, Barnwell JW, Incardona S, Perkins M, Bell D, McCarthy J, Cheng Q (2010) PLoS One 5:e8091

6. Pava Z, Echeverry DF, Diaz G, Murillo C (2010) Am J Trop Med Hyg 83:834 837

7. Bhavsar K, Fairchild A, Alonas E, Bishop DK, La Belle JT, Sweeney J, Alford TL, Joshi L (2009) Biosens Bioelectron 25:506 509

8. Ferreira AA, Colli W, da Costa PI, Yamanaka H (2005) Biosens Bioelectron 21:175 181

9. He YB, Luo HQ, Li NB (2007) Biosens Bioelectron 22:2952 2957

10. Tian L, Heyduk T (2009) Anal Chem 81:5218 5225

11. Brown HJ, Coppel RL (1991) Mol Biochem Parasitol 49:99 110

12. Yang JC, Blanton RE, King CL, Fujioka H, Aikawa M, Sam Yellowe TY (1996) Infect Immun 64:3584 3591

13. Sharma MK, Agarwal GS, Rao VK, Upadhyay S, Merwyn S, Gopalan N, Rai GP, Vijayaraghavan R, Prakash S (2010) Analyst 135:608 614 
14. Lee N, Baker J, Andrews KT, Gatton ML, Bell D, Cheng Q, McCarthy J (2006) J Clin Microbiol 44:2773 2778

15. Wang T, Fujioka H, Drazba JA, Sam Yellowe TY (2006) Parasitol Res 99:238 252

16. Bradford MM (1976) Anal Biochem 72:248 254

17. Sam Yellowe TY, Shio H, Perkins ME (1988) J Cell Biol 106:1507 1513
18. Katz EY (1990) J Electroanal Chem 291:257 260

19. Wink T, van Zuilen SJ, Bult A, van Bennkom WP (1997) Analyst 122:43R 50R

20. Willner I, Riklin A (1994) Anal Chem 66:1535 1539

21. Bard AJ, Faulkner LR (2001) Electrochemical methods: funda mentals and applications, 2nd edn. Wiley, New York 